\section{National Institute for the Infectious Diseases "L. Spallanzani", IRCCS. Recommendations for COVID-19 clinical management}

\author{
Emanuele Nicastri, Nicola Petrosillo, \\ Tommaso Ascoli Bartoli, \\ Luciana Lepore, Annalisa Mondi, \\ Fabrizio Palmieri, Gianpiero D'Offizi, \\ Luisa Marchioni, Silvia Murachelli, \\ Giuseppe Ippolito, Andrea Antinori \\ for the INMI COVID-19 \\ Treatment Group (ICOTREG)*
} National Institute for Infectious Diseases "L. Spallanzani”, IRCCS, Rome, Italy

\begin{abstract}
On January 9 2020, the World Health Organization (WHO) declared the identification, by Chinese Health authorities, of a novel coronavirus, further classified as SARS-CoV-2 responsible of a disease (COVID-19) ranging from asymptomatic cases to severe respiratory involvement. On March 9 2020, WHO declared COVID-19 a global pandemic. Italy is the second most affected country by COVID-19 infection after China. The "L. Spallanzani" National Institute for the Infectious Diseases, IRCCS, Rome, Italy, has been the first Italian hospital to admit and manage patients affected by COVID-19. Hereby, we show our recommendations for the management of COVID-19 patients, based on very limited clinical evidences; they should be considered as expert opinions, which may be modified according to newly produced literature data.
\end{abstract}

\section{Introduction}

On January 9 2020, the World Health Organization (WHO) declared the identification, by Chinese Health authorities, of a novel coronavirus, further classified as SARS-CoV-2. This new virus, initially emerged in the Chinese city of Wuhan in December 2019, led to a sharply spreading outbreak of human respiratory disease (COVID-2019), both within People's Republic of China and in several other countries worldwide. On March 92020 , WHO declared COVID-19 a global pandemic. Currently, Italy is the second most affected country by COVID-19 infection after China. The first autochthonous infection case was confirmed in Italy on February 212020 and up to now (March
12), 12462 cases with 827 deaths have been registered in Italy. Considering the recent evolution of Italian epidemiologic picture, many health-care facilities will be likely in charge of managing patients affected by COVID-19 in the next days. The " $L$. Spallanzani" National Institute for the Infectious Diseases, IRCCS has been the first Italian hospital to admit patients affected by COVID-19. Therefore, it will be useful to share the protocol for the clinical management of COVID-19 confirmed cases, applied within our Institute, in order to support other facilities that may have a limited experience in treating COVID-19 patients.

Procedures described in the present document are applied in agreement with the "Regional Network for the Infectious Diseases", the "Regional Hospital and Medical Specialties Network" and with the active cooperation of the "Regional Agency for the Health Emergencies - ARES 118". This latter is in charge for the response to the territorial health emergencies and for the transport of patients within the hospital network. Recommendations described within this document are based on very limited clinical evidences. Consequently, they should be considered as expert opinions, which may be modified according to newly produced literature data.

\section{COVID-19 case definition}

\section{Suspected case}

a. A person with an acute respiratory infection (defined as acute onset of at least one of the following sign/symptoms: fever, cough, respiratory difficulty breathing)

and without another etiology which completely explains the clinical presentation

and history of travels/stay in countries where there has been documented local transmission* within the 14 days preceding symptoms onset

OR

b. A person with an acute respiratory infection

and

a history of close contact with a probable or confirmed COVID-19 case in the within the 14 days preceding symptoms onset

OR

c. A person with a severe respiratory infection (fever and at least one sign/symptom of respiratory disease $e . g$. cough or difficulty breathing)

and

who require hospital admission

and

another etiology which completely explains
Correspondence: Nicola Petrosillo, National Institute for Infectious Diseases "L. Spallanzani”, IRCCS, Via Portuense 292, 00149 Rome, Italy.

Tel +390655170432 - Fax +390655170486. E-mail: nicola.petrosillo@inmi.it

Key words: COVID-19; SARS-CoV-2; Treatment.

Conflict of interest: The authors declare no potential conflict of interest.

Received for publication: 17 March 2020.

Accepted for publication: 17 March 2020.

This work is licensed under a Creative Commons Attribution-NonCommercial 4.0 International License (CC BY-NC 4.0).

C Copyright: the Author(s), 2020

Licensee PAGEPress, Italy

Infectious Disease Reports 2020; 12:8543

doi:10.4081/idr.2020.8543

the clinical presentation

In the setting of primary care/AE department in countries/areas where autochthonous transmission has been observed, all patients with sings/symptoms of acute respiratory infection should be considered as suspected cases.

*According to WHO reports available at: https://www.who.int/emergencies/diseases/novel-coronavirus-2019/situationreports/

\section{Probable case}

A suspected case in which the result of SARS-COV-2 Real Time PCR performed at Regional reference laboratories is doubtful or not conclusive or the result of a pan-coronavirus test is positive.

\section{Confirmed case}

A person with laboratory confirmation of SARS-CoV-2 infection, performed at National Reference Laboratory ("Istituto Superiore di Sanità"), irrespective of clinical signs and symptoms.

\section{Clinical management based on case severity}

\section{Asymptomatic or mild infection}

Cases not presenting any clinical feature suggesting a complicated course of the infection. Main goals of clinical management are:

1) Application of strict measures of infection prevention

2) Clinical monitoring, in order to early 
identify possible signs of clinical worsening

The application of strict measures of infection prevention should be applied for all patients with suspected or confirmed infection, regardless of clinical severity.

\section{Characteristics:}

- No symptoms or mild upper respiratory tract manifestations; stable clinical picture

Minimal additional microbiologic diagnostics:

- Influenza virus detection and/or respiratory agents multiplex PCR on single rhinopharyngeal swab sample

- SARS-CoV-2 serology if available

Clinical monitoring:

- Periodic clinical re-evaluation (once/work shift; thrice/day)

- Periodic vital signs recording (blood pressure, heart rate, respiratory rate, $\mathrm{SpO}_{2}$, GCS, body temperature) (once/work shift, thrice/day)

Virologic monitoring:

- SARS-CoV-2 RT-PCR performed on rhinopharyngeal swab every 48-72 hours until persistently negative

Diagnostic imaging:

- Unnecessary

- In case of cough and/or clinical examination suggesting possible lung Involvement, perform chest X-ray

Antiviral therapy:

- none

Supportive therapy:

- Symptoms control

\section{Stable patient presenting with respiratory and/or systemic symptoms (e.g. MEWS clinical deterioration score $<3$ )}

Individuals presenting COVID-19 clinical symptoms or signs. Considering the burden of clinical symptoms and the higher risk for complications, the goals of clinical management are, in addition to the ones stated for the asymptomatic patients:

1) Closer monitoring of clinical conditions and analytical data

2) Strategy aimed at accelerating viral clearance, through use of potentially efficacious experimental antiviral drugs

\section{Characteristics:}

- Prostration, severe asthenia, high fever $\left(>38^{\circ} \mathrm{C}\right)$ and/or persistent cough,

clinical or radiological signs of lung involvement

- No clinical or laboratoristic parameters of clinical severity and/or respiratory impairment

Additional microbiologic diagnostics:

- Influenza virus detection and/or respiratory agents multiplex PCR on single rhinopharyngeal swab sample
SARS-CoV-2 serology if available

- Urinary L. pneumophila and S. pneumoniae antigen detection

In case of availability of samples representative of lower respiratory tract (e.g. sputum), perform gram stain and culture; avoid aerosol-generating procedures to induce sputum, because of the higher infectious risk for healthcare workers

In case of fever $\left(>38^{\circ} \mathrm{C}\right)$, perform at least 2 blood cultures, possibly before starting new antimicrobial therapies

Clinical monitoring:

- Periodic clinical re-evaluation (once/work shift; thrice/day)

- Periodic vital signs recording (blood pressure, heart rate, respiratory rate, $\mathrm{SpO}_{2}$, GCS, body temperature) (once/work shift, thrice/day), in order to early identify a possible rapid worsening of respiratory functions requiring an increase of the level of care

- Arterial blood gas analysis monitoring (mainly between $5^{\text {th }}$ and $7^{\text {th }}$ day or if clinical worsening), to be evaluated together with the intensive care specialist in charge

Virologic monitoring:

- SARS-CoV-2 RT-PCR performed on rhinopharyngeal swab every 48-72 hours until persistently negative

\section{Imaging diagnostics:}

- Chest X-ray: useful as a first-line radiological examination, for the follow-up and for a rapid assessment of certain pulmonary/thoracic emergencies. Quick and easy to perform; in case of necessity, it can be performed using portable systems.

- Chest computed tomography, without contrast: high sensitivity in identifying and quantifying lung parenchymal involvement. No absolute indication at this stage of the disease, but highly valuable, together with blood gas analysis, to predict clinical worsening. Chest CT report should be evaluated together with the intensive care specialist in charge

\section{Antiviral therapy:}

- Lopinavir/ritonavir* 200/50 mg tablets, 2 tablets q12h, during 14 days and

Hydroxychloroquine phosphate** $400 \mathrm{mg}$ tablets, 1 tablet q12 as loading dose, followed by $200 \mathrm{mg}$ tablets, 1 tablet q12, during 10 days, or Chloroquine phosphate** $250 \mathrm{mg}$ tablets, 2 tablet q12, during 10 days

* Alternatively to Lopinavir/ritonavir, Darunavir $600 \mathrm{mg}$ tablets, 1 tablet q12 plus Ritonavir $100 \mathrm{mg}$ tablets, 1 tablet q12, during 14 days.
** Before chloroquine and hydrossichloroquine administration, G6PD deficiency test should be performed.

Supportive therapy:

- Symptomatic

Oral rehydration

- Consider antimicrobial therapy (broad spectrum-empiric or based on microbiological results)

- Prompt availability of $\mathrm{O}_{2}$, in case of necessity

\section{Patient affected by respiratory} symptoms, clinically unstable, not in critical conditions (e.g.: MEWS clinical deterioration score 3-4)

Patients presenting severe respiratory conditions related to SARS-CoV-2 infection and/or to its complications. Adjunctive goals of clinical management at this stage are:

1) Strict monitoring, especially between $5^{\text {th }}$ and $7^{\text {th }}$ day since symptoms onset, in order to ensure an immediate life support and an increase of the level of care, whenever required

2) Maintenance of an adequate peripheral oxygenation, through $\mathrm{O}_{2}$ administration

3) Use of potentially efficacious antiviral experimental drugs, aimed at rapidly reducing viral replication

4) Empirical or targeted treatment of possible bacterial co-infections;

5) Prompt assessment of the need of drugs aimed at modulating the immune and inflammatory response, in order to counteract the evolution to ARDS

\section{Characteristics:}

- Clinical and/or laboratoristic evidence of worsening of gas exchange (mild-tomoderate dyspnoea, high respiratory rate, shortness of breath, low peripheral $\mathrm{SpO}_{2}$ or altered arterial blood gases while breathing room air), without any critical or warning signs (severe respiratory failure, respiratory distress, consciousness disorders, hypotension, shock)

Additional microbiologic diagnostics:

- Influenza virus detection and/or respiratory agents multiplex PCR on single rhinopharyngeal swab sample

\section{SARS-CoV-2 serology if available}

Urinary L. pneumophila and S. pneumoniae antigen detection

In case of availability of sample representative of lower respiratory tract (e.g. sputum), perform gram stain and culture; avoid aerosol-generating procedures to induce sputum, because of the higher infectious risk for healthcare workers

- In case of fever $\left(>38^{\circ} \mathrm{C}\right)$, perform at least 2 blood cultures, possibly before 
starting new antimicrobial therapies

- Other eventual diagnostics based on the specific clinical picture (e.g. HIV test, $P$. jirovecii detection on respiratory fluids, MRSA on nasal swab, etc...)

Clinical monitoring:

- Strict clinical re-evaluation

- Strict periodic vital signs recording (blood pressure, heart rate, respiratory rate, $\mathrm{SpO}_{2}$, GCS, body temperature), in order to early identify a possible rapid worsening of respiratory functions, requiring an increase of the level of care

- Arterial blood gas analysis monitoring (mainly between $5^{\text {th }}$ and $7^{\text {th }}$ day), to be evaluated together with the intensive care specialist in charge

- Consultation with an intensive care specialist

Virologic, immunologic and biochemical monitoring:

- SARS-CoV-2 RT-PCR performed on rhinopharyngeal swab every 48-72 hours until persistently negative

- IL-6 plasma levels

- D-dimer, ferritin, fibrinogen, C-reactive protein, tryglicerides, lactate dehydrogenase (LDH)

Imaging diagnostics:

- Chest X-ray: useful as a first-line radiological examination, for the follow-up and for a rapid assessment of certain pulmonary/thoracic emergencies. Quick and easy to perform; in case of necessity, it can be performed using portable systems

- Chest computed tomography, without contrast: high sensitivity in identifying and quantifying lung parenchymal involvement. To be performed in every patient affected by lung involvement causing respiratory failure. Use of contrast only in case of specific clinical questions (e.g. pulmonary embolism). Chest CT report should be evaluated together with the intensive care specialist in charge

- Ecocardiography: indicated in case of suspected hearth failure as a contributing factor to lung involvement/respiratory failure

Antiviral therapy:

- Remdesivir ${ }^{\circ}$ (GS-57324), once daily intravenously: $200 \mathrm{mg}$ loading dose, followed by $100 \mathrm{mg}$ daily maintenance dose, during 10 days, or (if Remdesivir not available)

Lopinavir/ritonavir* 200/50 $\mathrm{mg}$ tablets, 2 tablets q12h, during 28 days and

Hydroxychloroquine phosphate** $400 \mathrm{mg}$ tablets, 1 tablet q12 as loading dose, followed by $200 \mathrm{mg}$ tablets, 1 tablet q12, during 10 days, or
Chloroquine phosphate** $250 \mathrm{mg}$ tablets, 2 tablet q12, during 10 days and

Tocilizumab $^{\wedge} 8 \mathrm{mg} / \mathrm{kg}$ (maximum 800 $\mathrm{mg} /$ dose), single dose intravenously (1hour infusion); in absence or with poor clinical improvement a second dose should be administered after 8-12 hours

* Alternatively to Lopinavir/ritonavir, Darunavir $600 \mathrm{mg}$ tablets, 1 tablet q12 plus Ritonavir $100 \mathrm{mg}$ tablets, 1 tablet q12, during 14 days.

** Before chloroquine and hydroxychloroquine administration, G6PD deficiency test should be performed

- Do not co-administrate Remdesivir with lopinavir/ritonavir, due to possible drug interactions

$\wedge$ Tocilizumab administration should be guided by the presence of 1 or more of following selection criteria: a) $\mathrm{PaO} 2 / \mathrm{Fi} 02$ ratio $<300 \mathrm{mmHg}$; b) rapid worsening of respiratory gas exchange with or without availability of non-invasive or invasive ventilation; d) IL-6 levels $>40 \mathrm{pg} / \mathrm{mL}$ (if not available, see Ddimer levels $>1000 \mathrm{ng} / \mathrm{mL}$.

Therapeutic schedule: 2 administrations (each $8 \mathrm{mg} / \mathrm{kg}$, maximum $800 \mathrm{mg}$ ). Second administration at 8-12 hours from the first one. Repeat PCR and Ddimer (+/-IL-6) after 24 hours from each administration.

\section{Supportive therapy:}

- $\mathrm{O}_{2}$ administration

- Aantimicrobial therapy (broad spectrum-empiric or based on microbiological results)

- Oral or intravenous rehydration

- Consider systemic steroids administration in case of clinical signs suggesting an incipient worsening of respiratory functions (steroids are mandatory if Tocilizumab is used) (methylprednisolone $1 \mathrm{mg} / \mathrm{Kg}$ daily intravenously for 5 days, followed by $40 \mathrm{mg}$ daily for 3 days and, lastly, $10 \mathrm{mg}$ daily for 2 days, or dexamethasone $20 \mathrm{mg}$ daily intravenously for 5 days, followed by $10 \mathrm{mg}$ daily for 3 days and lastly $5 \mathrm{mg}$ daily for 2 days)

\section{Critical patient (e.g. MEWS clinical deterioration score $>4$ )}

Patient affected by a very severe illness, due to severe respiratory failure or severe impairment of other vital functions. Main goals during this stage are, in conjunction to the procedures described for the unstable patient:

1) Life support and intensive monitoring

2) Rapid recognition and immediate management of complications

3) Active search for adjunctive or alterna- tive diagnosis

4) Use of drugs aimed at reducing the impact of inflammatory response to ARDS

\section{Characteristics:}

- Acute respiratory distress syndrome (ARDS)

Severe respiratory failure, respiratory distress

- Hypotension - Shock

Multiorgan failure (MOF)

- Consciousness impairment

Additional microbiologic diagnostics:

Influenza virus detection and/or respiratory agents multiplex PCR on single rhinopharyngeal swab sample

SARS-CoV-2 serology if available

- Urinary L. pneumophila and S. pneumoniae antigen detection

In case of availability of samples representative of lower respiratory tract (e.g. sputum), perform gram stain and culture; avoid aerosol-generating procedures to induce sputum, because of the higher infectious risk for healthcare workers

- In case of fever $\left(>38^{\circ} \mathrm{C}\right)$, perform at least 2 blood cultures, possibly before starting new antimicrobial therapies

- Other eventual diagnostics based on the specific clinical picture (e.g. HIV test, $P$. jirovecii detection on respiratory fluids, MRSA on nasal swab, etc...)

Clinical monitoring:

- Strict monitoring and intensive care, starting from patients with moderate ARDS, according to Berlin definition $\left(100 \mathrm{mmHg}<\mathrm{PaO}_{2} / \mathrm{FiO}_{2} \leq 200 \mathrm{mmHg}\right)$

Virologic, immunologic and biochemical monitoring:

SARS-CoV-2 RT-PCR performed on rhinopharyngeal swab every 48-72 hours until persistently negative

- SARS-CoV-2 RT-PCR performed on samples representing lower respiratory tract, using the same timing

\section{IL-6 plasma levels}

- D-dimer, ferritin, fibrinogen, C-reactive protein, tryglicerides, lactate dehydrogenase (LDH)

Imaging diagnostics:

- Chest computed tomography, without contrast: high sensitivity in identifying and quantifying lung parenchymal involvement. To be performed in every patient affected by lung involvement causing respiratory failure. Use of contrast only in case of specific clinical questions (e.g. pulmonary embolism). The exam is required by the intensive care specialist in charge

Ecocardiography: indicated in case of suspected hearth failure as a contributing factor to lung involvement/respiratory failure 


\section{Antiviral therapy:}

- Remdesivir ${ }^{\circ}$ (GS-57324), once daily intravenously: $200 \mathrm{mg}$ loading dose, followed by $100 \mathrm{mg}$ daily maintenance dose, during 10 days, or (if Remdesivir not available)

Lopinavir/ritonavir* 200/50 $\mathrm{mg}$ tablets, 2 tablets q12h, during 14 days and

Hydroxychloroquine phosphate** $400 \mathrm{mg}$ tablets, 1 tablet q12 as loading dose, followed by $200 \mathrm{mg}$ tablets, 1 tablet q12, during 10 days, or Chloroquine phosphate** $250 \mathrm{mg}$ tablets, 2 tablet q12, during 10 days and

Tocilizumab $^{\wedge} 8 \mathrm{mg} / \mathrm{kg}$ (maximum 800 $\mathrm{mg} /$ dose), single dose intravenously (1hour infusion); in absence or with poor clinical improvement a second dose should be administered after 8-12 hours

* Alternatively to Lopinavir/ritonavir, Darunavir $600 \mathrm{mg}$ tablets, 1 tablet q12 plus Ritonavir $100 \mathrm{mg}$ tablets, 1 tablet q12, during 14 days.

** Before chloroquine and hydrossichloroquine administration, G6PD deficiency test should be performed

- Do not co-administrate Remdesivir with lopinavir/ritonavir, due to possible drug interactions

$\wedge$ Tocilizumab administration should be guided by the following selection criteria: a) $\mathrm{PaO} 2 / \mathrm{Fi} 02$ ratio $<300 \mathrm{mmHg}$; b) rapid worsening of respiratory gas exchange with or without availability of non-invasive or invasive ventilation; d) IL-6 levels $>40 \mathrm{pg} / \mathrm{mL}$ (if not available, see D-dimer levels $>1000 \mathrm{ng} / \mathrm{mL}$.

\section{Supportive therapy:}

- Gold standard: early protective mechanical ventilation as recommended for patients affected by ARDS sustainted by viral interstitial pneumonia

- Antimicrobial therapy (broad spectrumempiric or based on microbiological results)

- Intensive care and monitoring as indicated by hospital protocols

- Systemic steroid therapy in case of ARDS/severe respiratory failure (steroids are mandatory if Tocilizumab is used) (methylprednisolone $1 \mathrm{mg} / \mathrm{Kg}$ daily intravenously for 5 days, followed by $40 \mathrm{mg}$ daily for 3 days and, lastly, 10 $\mathrm{mg}$ daily for 2 days, or dexamethasone $20 \mathrm{mg}$ daily intravenously for 5 days, followed by $10 \mathrm{mg}$ daily for 3 days and lastly $5 \mathrm{mg}$ daily for 2 days)

- Consider ECMO in case of refractory hypoxemia despite invasive mechanical ventilation. Indication is given by the intensive care specialist in charge, according to ECMONET criteria and to ECMO regional center

\section{ARDS criteria (Berlin definition $-\mathbf{2 0 1 2}+$ Kigali adaptation for low resource settings)}

Onset: new or worsening respiratory symptoms within one week of known clinical insult

Chest imaging (radiograph, CT scan, or lung ultrasound): bilateral opacities, not fully explained by effusions, lobar or lung collapse, or nodules

Origin of oedema: respiratory failure not fully explained by cardiac failure or fluid overload. Need objective assessment (e.g. echocardiography) to exclude hydrostatic cause of oedema if no risk factor is present Oxygenation (adults):

- $\quad$ Mild ARDS: $200 \mathrm{mmHg}<\mathrm{PaO}_{2} / \mathrm{FiO}_{2} \leq$ $300 \mathrm{mmHg}$ (with PEEP or CPAP $\geq 5$ $\mathrm{cmH}_{2} \mathrm{O}$, or non-ventilated)

- Moderate ARDS: $100 \mathrm{mmHg}<$ $\mathrm{PaO}_{2} / \mathrm{FiO}_{2} \leq 200 \mathrm{mmHg}$ with PEEP $\geq 5$ $\mathrm{cmH}_{2} \mathrm{O}$, or non-ventilated)

- Severe ARDS: $\mathrm{PaO}_{2} / \mathrm{FiO}_{2} \leq 100 \mathrm{mmHg}$ with PEEP $\geq 5 \mathrm{cmH} 2 \mathrm{O}$, or non-ventilated)

- When $\mathrm{PaO}_{2}$ is not available, $\mathrm{SpO}_{2} / \mathrm{FiO}_{2}$ $\leq 315$ suggests ARDS (including in nonventilated patients)

Oxygenation (children; note OI = Oxygenation Index and OSI = Oxygenation Index using $\mathrm{SpO}_{2}$ ):

- Bilevel NIV or CPAP $\geq 5 \mathrm{cmH}_{2} \mathrm{O}$ via full face mask: $\mathrm{PaO}_{2} / \mathrm{FiO}_{2} \leq 300 \mathrm{mmHg}$ or $\mathrm{SpO}_{2} / \mathrm{FiO}_{2} \leq 264$

- Mild ARDS (invasively ventilated): $4 \leq$ OI $<8$ or $5 \leq$ OSI $<7.5$

- Moderate ARDS (invasively ventilated): $8 \leq$ OI $<16$ or $7.5 \leq$ OSI $<12.3$

Severe ARDS (invasively ventilated): $\mathrm{OI} \geq 16$ or $\mathrm{OSI} \geq 12.3$

\section{Antiviral/Immunological Therapy}

There are currently no medications or vaccines proven to be effective for COVID19. Some either old or new agents have been proposed and explored for treatment of COVID-19 but clinical trials are still underway. Up to now, the only available data are based on anecdotal experiences and expert opinions.

\section{Chloroquine and hydroxychloro- quine}

Chloroquine is an old and widely used anti-malarial drug and it is also efficacious as an anti-inflammatory agent for rheumatologic disease. Earlier studies have demonstrated a potential antiviral effect of this drug against SARS and avian influenza H5N1.

\section{Mechanism of Action}

It has been postulated that antiviral action of chloroquine may depend by several mechanisms such as the change of cell membrane $\mathrm{pH}$ which is necessary for viral fusion and the interference with glycosylation of viral proteins. Hydroxychloroquine, an analogue of chloroquine, has been proved to have similar if not better in-vitro efficacy on SARS-Cov-2.

\section{Available data on SARS-COV2}

A recent study has demonstrated invitro efficacy of chloroquine and remdesivir in inhibiting replication of SARS-COV2. Moreover, emerging reports from China suggests that chloroquine has shown a superiority in reducing both the severity and the duration of clinical disease without significant adverse events in almost one hundred patients. In light of this results, an expert consensus group in China has recommended chloroquine for COVID-19 treatment.

\section{Dosage}

The recommended dosage for SARS$\mathrm{CoV}-2$ infection is chloroquine $500 \mathrm{mg}$ bid or hydroxychloroquine $200 \mathrm{mg}$ bid for 10 days in combination with another antiviral agent (Lopinavir/ritonavir or Remdesivir).

\section{Adverse Events/Cautions}

Serious adverse effects may include: QT prolongation \& torsades de pointes, reduction in seizure threshold, anaphylaxis or anaphylactoid reaction, neuromuscular impairment, neuropsychiatric disorders (potential to increase delirium), pancytopenia, neutropenia, thrombocytopenia, aplastic anemia, hepatitis.

Common adverse reactions: nausea/ vomiting, diarrhea, abdominal pain, visual disturbance, headache, extrapyramidal symptoms

It is important to check G6PDH before starting treatment and during treatment to monitor complete blood count, QT interval.

Contraindicated in: Porphyria, G6PD deficiency, epilepsy, heart failure, recent myocardial infarction.

\section{Lopinavir/ritonavir}

Lopinavir/ritonavir is a well-known protease inhibitor which has been widely used for many years for the treatment of HIV infection. Compared to remdesivir, lopinavir/ritonavir has the advantage that it's widely available and has an established toxicity and drug-drug interactions profile. Its antiviral action against coronavirus infections has been previously demonstrated both in-vitro and in-vivo (animal and human data) in studies conducted on SARS 
(in combination with ribavirin) and MERS infection. Moreover, a randomized clinical trial (RCTs) on lopinavir/ritonavir combined with IFNb use in MERS infection is currently ongoing [MIRACLE Trial].

\section{Mechanism of Action}

Lopinavir act its antiviral activity by inhibiting viral replication. As in HIV infection, ritonavir only acts boosting lopinavir plasma levels.

\section{Available data on SARS-COV2}

Although only limited and anecdotal data are available of the clinical efficacy of lopinavir/ritonavir in COVID-19 infection so far, it seems to rapidly reduce SARSCoV2 replication. Lopinavir/ritonavir is currently under investigation within several RCTs in China.

\section{Dosage}

The recommended dose for COVID-19 is the $400 / 100 \mathrm{mg}$ bid (the standard dose used for HIV therapy). In case of swallowing difficulties or unconscious patient the oral solution of lopinavir/ritonavir should be administrated (tablets cannot be crushed).

\section{Adverse Events/Cautions}

Serious adverse effects may include: Hypersensitivity reaction, angioedema, Stevens-Johnson syndrome and Toxic epidermal necrolysis, EKG alterations (QT prolongation \& Torsade de Pointes, AV block, PR prolongation), pancytopenia, Pancreatitis, Hepatotoxicity

Common adverse reactions: gastrointestinal symptoms (nausea/vomiting, diarrhea)

Monitoring transaminase levels during treatment and drug-drug interactions before treatment start.

In the light of the possible shortage of lopinavir/ritonavir stocks due to the increasing prescriptions, we suggest the possible use of darunavir/ritonavir at the dosage of $600 \mathrm{mg}$ ever 12 hours in replacement of lopinavir/ritonavir considering the similar mechanism of action and the optimal safety profile.

\section{Remdesivir (GS-5734)}

Remdesivir is a novel nucleotide analogue currently under evaluation in clinical trials for Ebola infection. Remdesevir has shown clinical an excellent activity against other coronavirus infections (SARS, MERS) both in-vitro and in animal models.

\section{Mechanism of Action}

It acts by inhibiting viral polymerase

\section{Available data on SARS-COV2}

A recent study exploring in-vitro activi- ty of remdesivir and chloroquine has demonstrated efficacy of the drugs in inhibiting replication of SARS-COV2. A recent case report described the use of remdesivir, requested for compassionate use, in the first patients with COVID-19 in the United States. Two ongoing clinical randomized clinical trials in China are evaluating remdesivir for moderate and sever COVID-19 infections.

To check drug-drug interactions of antiviral therapy please visit the University of Liverpool website: http://www.covid19-druginteractions.org

\section{Tocilizumab}

\section{Rationale for the use and mechanism of action}

Tocilizumab (TCZ) is an anti-human IL-6 receptor monoclonal antibody that inhibits signal transduction by binding sIL$6 \mathrm{R}$ and mIL-6R. The main approved indication is for rheumatoid arthritis, in association or not with methotrexate.

In 2017, the U.S. Food and Drug Administration approved TCZ for the treatment of cytokine release syndrome (CRS) consisting in a systemic inflammatory response caused by the massive release of pro-inflammatory cytokines in response to iatrogenic (e.g. CAR-t therapies) or infective stimuli.

\section{Available data on SARS-COV2}

Although the lack of data on SARSCoV-2 pathogenesis, studies in China showed a possible correlation of massive inflammation and severe lung damage on the rapid evolution of fatal pneumonia.

Indeed, in COVID-19 patients, significant differences in IL-6 plasmatic levels were observed at different stage of disease with a higher expression in severe cases than mild ones. Moreover, in the biopsy samples at autopsy from a severe COVID19 patient, histological examination showed diffuse alveolar damage with cellular fibromyxoid exudates and interstitial mononuclear inflammatory infiltrates suggesting severe immune injury.

Despite the lack of clinical trials on TCZ efficacy and safety for COVID-19 treatment, in China TCZ was recently approved for patients affected by severe SARS-CoV-2 pulmonary complications by the National Health Commission of the People's Republic of China.

Preliminary data from an observational study conducted in China on 21 severe cases receiving TCZ, showed an improvement of the clinical and radiological outcome.

\section{Indications}

TCZ is a potential treatment strategy in severe and critical COVID-19 patients. In particular, patients who could benefit from TCZ therapy are:

1) Patients with respiratory symptoms, unstable and severe but not in critical conditions (e.g. clinical instability score of MEWS 3-4) with evidence of worsening of gas exchange with mild to moderate dyspnoea, tachypnea, worsening of $\mathrm{SpO} 2$ or arterial blood gas analysis parameters in ambient air $(\mathrm{SpO} 2 \leq$ $93 \%$ in ambient air, $\mathrm{PaO} 2 / \mathrm{FiO} 2 \leq 300$ $\mathrm{mmHg}$ ) in the absence of critical manifestations or signs of alarm (severe respiratory failure, respiratory distress, altered state of consciousness, hypotension, cardiovascular shock);

2) Patient with respiratory symptoms in critical conditions (e.g. clinical instability score of MEWS > 4) with evidence of ARDS (from moderate ARDS according to the Berlin definition: 100 $\mathrm{mmHg}<\mathrm{PaO} 2 / \mathrm{FiO} 2 \leq 200 \mathrm{mmHg}$ ) or severe respiratory failure or evidence of rapid worsening as respiratory distress with the need for mechanical ventilation or the presence of shock or the presence of concomitant organ failure with the need for intensive care monitoring.

\section{Dosage}

Although the optimal dose and schedule of TCZ for treatment of CRS is not known, the intended posology is $8 \mathrm{mg} / \mathrm{kg}$ intravenously (maximum $800 \mathrm{mg} / \mathrm{dose}$ ) infused over an hour. Additional administration(s) are evaluated on the basis of patient's response to TCZ 8-12 hours apart, in case of:

- Absence/poor clinical improvement or clinical worsening and/or

- Failure in reduction of $50 \%$ baseline Creactive protein (a reliable surrogate marker of IL-6) or failure in normalization and/or

- Failure in reduction in D-dimer, fibrinogen or ferritin levels.

Dosage adjustment is required in relation to blood parameters of liver function and blood count according to the indications specified in the patient package insert.

It is advisable monitoring of the following blood parameters (full blood count including platelet count, ALT/AST, LDH, fibrinogen, D-dimer, ferritin, C-reactive protein and IL-6) at different time points: immediately before $1^{\text {st }}$ infusion, immediately before $2^{\text {nd }}$ infusion, $24 \mathrm{~h}$ after $2^{\text {nd }}$ infusion, $36 \mathrm{~h}$ after $2^{\text {nd }}$ infusion.

\section{Adverse events/cautions}

Severe life-threatening infections and 
alterations in blood parameters as ALT / AST $>5$ ULN, absolute neutrophils count $<500 \mathrm{cell} / \mathrm{mmc}$ and platelet count $<50000$ cell/mmc are contraindications for $\mathrm{TCZ}$ treatment. Caution is required in special categories: pregnancy/breastfeeding, active /latent pulmonary tuberculosis, bacterial/fungal infections, immune-related rheumatic disease or concomitant therapy with anti-rejection drugs or immunomodulating therapies, hepatopaties (including viral hepatitis). The safety profile of TCZ is well known. In the TQT study, the most common marked laboratory abnormality was low neutrophil counts. Decreases were observed in mean neutrophil counts following single doses of TCZ over the first 2 days post-treatment, reaching a maximum at approximately 24 hours after the infusion. The observed incidence of marked decreases in neutrophil counts increased with the higher dose of TCZ. Thrombocytopenia and increase of liver function tests have also been described.

For more detailed information, the reader should refer to the patient package insert.

\section{*INMI COVID-19 Treatment Group - ICOTREG}

Abdeddaim A, Agrati C, Albarello F, Antinori A, Ascoli Bartoli T, Baldini F, Bellagamba $R$, Bevilacqua $N$, Bibas $M$, Biava G, Boumis E, Busso D, Camici M, Capobianchi MR, Capone A, Caravella I, Cataldo A, Cerilli S, Chinello G, Cicalini S, Corpolongo A, Cristofaro M, D'Abramo A, Dantimi $C$, De Angelis $G$, De Palo $M G$, D'Offizi G, De Zottis F, Di Lorenzo R, Di Stefano F, Fusetti M, Galati V, Gagliardini $R$, Garotto G, Gebremeskel Tekle Saba, Giancola ML, Giansante F, Girardi E, Goletti D, Granata G, Greci MC, Grilli E, Grisetti $S$, Gualano $G$, Iacomi $F$, Iannicelli $G$, Ippolito $G$, Lepore $L$, Libertone $R$, Lionetti $R$, Liuzzi $G$, Loiacono $L$, Macchione M, Marchioni L, Mariano A, Marini MC, Maritti M, Mastrobattista A, Mazzotta V, Mencarini P, MigliorisiRamazzini P, Mondi A, Montalbano M, Mosti S, Murachelli S, Musso M, Nicastri E, Noto P, Oliva A, Palazzolo C, Palmieri F, Pareo C, Petrone A, Pianura E, Pinnetti $C$, Pontarelli A, Puro V, Rianda A, Rosati S, Sampaolesi A, Santagata $C$, Scarcia $D$ 'Aprano S, Scarabello A, Schininà $V$, Scorzolini L, Stazi GV, Taibi C, Taglietti F, Tonnarini $R$, Topino $S$, Vergori A, Vincenzi L, Visco-Comandini U, Vittozzi P, Zaccarelli $M$, Zaccaro $G$.

\section{References}

European Centre for Disease Prevention and Control. Rapid Risk Assessment: Novel coronavirus disease 2019 (COVID-2019) pandemic: increased transmission in the EU/EEA - sixth update. ECDC: Stockholm; 2020, 12 March 2020. Available at: https:/www.ecdc.europa.eu/sites/defau lt/files/documents/RRA-sixth-updateOutbreak-of-novel-coronavirus-disease-2019-COVID-19.pdf

Ministero della Salute. Direzione Generale della Prevenzione Sanitaria. Ufficio 5: Prevenzione delle Malattie Trasmissibili e Profilassi Internazionale. Aggiornamento Circolare 09.03.2020. Allegato 1 . Definizione di caso di COVID-19 per la segnalazione. Available at http://www. salute.gov.it/portale/documentazione/p6 2_6.jsp?lingua $=$ italiano\&area $=27 \& b$ tnCe $\mathrm{rca}=\mathrm{cerca}$, visited on March 132020.

WHO. Global Surveillance for human infection with coronavirus disease (COVID-2019). Revised guidance, 27 February 2020. Available at https:/ /www.who.int/publications-detail/global-surveillance-for-human-infectionwith-novel-coronavirus-(2019-ncov), visited on 28 February 2020.

European Centre for Disease Prevention and Control. An agency of the European Union. Case definition for EU surveillance of COVID-19, as of 25 February 2020. Available at https://www.ecdc. europa.eu/en/case-definition-and-european-surveillance-human-infectionnovel-coronavirus-2019-ncov, visited on 28 February 2020.

Centers for Disease Control and Prevention (CDC). Interim Infection Prevention and Control Recommendations for Patients with Confirmed Coronavirus Disease 2019 (COVID-19) or Persons Under Investigation for COVID-19 in Healthcare Settings. Updated February 21, 2020. Available at https://www.cdc. gov/coronavirus/2019-ncov/infectioncontrol/control-recommendations. html?CDC AA refVal $=$ https $\% 3 \mathrm{~A} \% 2 \mathrm{~F}$ $\% 2 \mathrm{Fwww} . \mathrm{cdc}$.gov $\% 2 \mathrm{~F}$ coronavirus $\% 2 \mathrm{~F}$ 2019-ncov\%2Fhcp\%2Finfection-control.html, visited on February 282020.

Wang Z, Chen X, Lu Y, et al. Clinical characteristics and therapeutic procedure for four cases with 2019 novel coronavirus pneumonia receiving combined Chinese and Western medicine treatment. Biosci Trends 2020 Feb 9. doi:
$10.5582 /$ bst.2020.01030.

Lu H. Drug treatment options for the 2019new coronavirus (2019-nCoV). Biosci Trends 2020 Jan 28. doi: 10.5582/bst. 2020.01020.

Huang C, Wang Y, Li X, et al. Clinical features of patients infected with 2019 novel coronavirus in Wuhan, China. Lancet 2020;395:497-506.

Chu CM, Cheng VC, Hung IF, et al. Role of lopinavir/ritonavir in the treatment of SARS: initial virological and clinical findings. Thorax 2004;59:252-6.

Momattin H, Mohammed K, Zumla A, et al. Therapeutic options for Middle East respiratory syndrome coronavirus (MERS-CoV) - possible lessons from a systematic review of SARS-CoV therapy. Int J Infect Dis 2013;17:e792-8.

Momattin H, Al-Ali AY, Al-Tawfiq JA. A Systematic Review of therapeutic agents for the treatment of the Middle East Respiratory Syndrome Coronavirus (MERS-CoV). Travel Med Infect Dis 2019;30:9-18..

Wang M, Cao R, Zhang L, et al. Remdesivir and chloroquine effectively inhibit the recently emerged novel coronavirus (2019-nCoV) in vitro. Cell Res 2020 Feb 4. doi: 10.1038/s41422-020-02820 .

Holshue ML, DeBolt C, Lindquist S, et al. First Case of 2019 Novel Coronavirus in the United States. N Engl J Med 2020 Jan 31. doi: 10.1056/NEJMoa2001191.

Sheahan TP, Sims AC, Leist SR, et al. Comparative therapeutic efficacy of remdesivir and combination lopinavir, ritonavir, and interferon beta against MERS-CoV. Nat Commun 2020;11: 222.

Lai CC, Shih TP, Ko WC, et al. Severe acute respiratory syndrome coronavirus 2 (SARS-CoV-2) and coronavirus disease-2019 (COVID-19): The epidemic and the challenges. Int $\mathrm{J}$ Antimicrob Agents 2020:105924. doi: 10.1016/ j.ijantimicag.2020.105924.

NIH National Institutes of Health. NIH clinical trial of remdesivir to treat COVID-19 begins. Study enrolling hospitalized adults with COVID-19 in Nebraska. Tuesday, February 25, 2020. Available at https://www.nih.gov/newsevents/news-releases/nih-clinical-trialremdesivir-treat-covid-19-begins, visited on February 282020.

Zhao JP, Hu Y, Du RH, et al. Expert consensus on the use of corticosteroid in patients with 2019-nCoV pneumonia. 
Zhonghua Jie He He Hu Xi Za Zhi. 2020;43:E007.

ARDS Definition Task Force. Acute respiratory distress syndrome: the Berlin Definition. JAMA 2012;307:2526-33.

Riviello ED, Kiviri W, Twagirumugabe T, et al. Hospital Incidence and Outcomes of the Acute Respiratory Distress Syndrome Using the Kigali Modification of the Berlin Definition. Am J Respir Crit Care Med 2016;193: 52-9.

Khemani RG, Smith LS, Zimmerman JJ, et al. Pediatric acute respiratory distress syndrome: definition, incidence, and epidemiology: proceedings from the Pediatric Acute Lung Injury Consensus Conference. Pediatr Crit Care Med 2015;16:S23-40..

Vincent MJ, Bergeron E, Benjannet S, et al. Chloroquine is a potent inhibitor of SARS coronavirus infection and spread. J Virol 2005;2:69.

Yan Y, Zou Z, Sun Y, et al. Anti-malaria drug chloroquine is highly effective in treating avian influenza A H5N1 virus infection in an animal model. Cell Res 2013;23:300-2.

Wang M, Cao R, Zhang L, et al. Remdesivir and chloroquine effectively inhibit the recently emerged novel coronavirus (2019-nCoV) in vitro. Cell Res. 2020.

Yao X, Ye F, Zhang $M$, et al. In Vitro Antiviral Activity and Projection of Optimized Dosing Design of Hydroxychloroquine for the Treatment of Severe Acute Respiratory Syndrome Coronavirus 2 (SARS-CoV-2). Clin Infect Dis 2020 Mar 9.

Gao J, Tian Z, Yang X. Breakthrough: Chloroquine phosphate has shown apparent efficacy in treatment of COVID-19 associated pneumonia in clinical studies. Biosci Trends $2020 \mathrm{Feb}$ 19. doi: 0.5582/bst.2020.01047. [Epub ahead of print]

Multicenter collaboration group of Department of Science and Technology of Guangdong Province and Health Commission of Guangdong Province for chloroquine in the treatment of novel coronavirus pneumonia. [Expert consensus on chloroquine phosphate for the treatment of novel coronavirus pneumonia]. Zhonghua Jie $\mathrm{He} \mathrm{He} \mathrm{Hu}$ Xi Za Zhi. 2020 Feb 20;43:E019.

Chu CM, Cheng VC, Hung IF, et al. Role of lopinavir/ritonavir in the treatment of SARS: initial virological and clinical findings. Thorax 2004;59:252-6.

Chan KS, Lai ST, Chu CM, et al. Treatment of severe acute respiratory syndrome with lopinavir/ritonavir: a multicentre retrospective matched cohort study. Hong Kong Med J 2003;9:399-406.

Chan JF, Yao Y, Yeung ML, et al. Treatment With Lopinavir/Ritonavir or Interferon$\beta 1 \mathrm{~b}$ Improves Outcome of MERS-CoV Infection in a Nonhuman Primate Model of Common Marmoset. J Infect Dis 2015;212:1904-13.

Han W, Quan B, Guo Y, et al. The course of clinical diagnosis and treatment of a case infected with coronavirus disease 2019. J Med Virol 2020 Feb 19.

Lim J, Jeon S, Shin HY, et al. Case of the Index Patient Who Caused Tertiary Transmission of COVID-19 Infection in Korea: the Application of Lopinavir/Ritonavir for the treatment of COVID-19 Infected Pneumonia Monitored by Quantitative RT-PCR. J Korean Med Sci 2020;35:e79

Sheahan TP, Sims AC, Leist SR, et al. Comparative therapeutic efficacy of remdesivir and combination lopinavir, ritonavir, and interferon beta against MERS CoV. Nat Commun 2020;11: 222.

de Wit E, Feldmann F, Cronin J, et al. Prophylactic and therapeutic remdesivir (GS-5734) treatment in the rhesus macaque model of MERS-CoV infection. Proc Natl Acad Sci U S A 2020 Feb 13. pii: 201922083

Agostini ML, Andres EL, Sims AC, Graham RL, Sheahan TP, Lu X, Smith EC, et al. Coronavirus susceptibility to the antiviral remdesivir (GS-5734) is mediated by the viral polymerase and the proofreading exoribonuclease. mBio 2018;9:e00221-18.

Holshue ML, DeBolt C, Lindquist S, et al. First Case of 2019 Novel Coronavirus in the United States. N Engl J Med 2020;382:929-36.

European Medicine Agency. Available at: ihttps://www.ema.europa.eu/en/documents/product-information/roactemraepar-product-information_it.pdf (Last Access 10th March 2020)

Le RQ, Li L, Yuan W, et al. FDA approval summary: tocilizumab for treatment of chimeric antigen receptor $\mathrm{T}$ cell $\square$ induced severe or life $\square$ threatening cytokine release syndrome. The Oncologist 2018;23:943.

Shang L, Zhao J, Hu Y, et al. On the use of corticosteroids for 2019-nCoV pneumonia. The Lancet 2020

Wang D, Hu B, Hu C, et al. Clinical characteristics of 138 hospitalized patients with 2019 novel coronavirus-infected pneumonia in Wuhan, China. JAMA 2020 Feb 7.

Xu Z, Shi L, Wang Y, et al. Pathological findings of COVID-19 associated with acute respiratory distress syndrome. Lancet Resp Med 2020. doi.org/10.1016/S2213-2600(20) 30076-X

Xiaoling X, Mingfeng $\mathrm{H}$, Tiantian L, et al. Effective Treatment of Severe COVID-19 Patients with Tocilizumab. 2020. chinaXiv:202003.00026v1

Riegler LL, Jones GP, Lee DW. Current approaches in the grading and management of cytokine release syndrome after chimeric antigen receptor T-cell therapy. Therapeut Clin Risk Manag 2019; 15:323.

European Medicine Agency. Assessment Report. RoActemra. Procedure No. EMEA/H/C/000955/II/0078. 28 June 2018.

Subbe CP, Kruger M, Rutherford P, Gemmel L. Validation of a modified Early Warning Score in medical admissions. QJM 2001;94:521-6. 